Kim A. Papp

\title{
The long-term efficacy and safety of new biological therapies for psoriasis
}

Received: 13 December 2005/ Revised: 10 March 2006/ Accepted: 13 March 2006/Published online: 25 April 2006 (C) Springer-Verlag 2006

\begin{abstract}
Long-term therapy is often required for psoriasis. This article reviews the most recent long-term clinical data for biological agents that have been approved or for which late-stage development data have been released for the treatment of patients with moderate to severe plaque psoriasis. Efficacy data are available for up to five 12-week courses of alefacept (approximately 60 weeks of therapy), 36 months (144 weeks) of continuous efalizumab, 48 weeks of continuous etanercept, and 50 weeks of bimonthly infliximab. Data sources include publications, product labeling, and posters presented at recent international scientific meetings. Alefacept appears to continue to be efficacious over multiple treatment courses for some responsive patients. The efficacy of efalizumab achieved during the first 12-24 weeks of therapy appears to be maintained or improved through at least 60 weeks of continuous treatment. The efficacy of etanercept appears to be maintained through at least 48 weeks of continuous treatment. Infliximab demonstrates a high response rate soon after initiation, which appears to be maintained through 24 weeks but declines modestly with therapy out to 50 weeks. After 48 weeks, approximately $60 \%$ of efalizumab-treated and $45 \%$ of etanercept-treated patients remaining on therapy achieved $\geq 75 \%$ improvement from baseline in Psoriasis Area and Severity Index, as did $70.5 \%$ of infliximab patients who did not miss more than two infusions. Safety data suggest that these agents may be used for long-term administration. Longterm data from psoriasis trials continue to accumulate. Recent data suggest that biological therapies have effi-
\end{abstract}

The development of this article was supported by Genentech, Inc., and Serono International S.A.

K. A. Papp

Probity Medical Research, University of Western Ontario,

135 Union Street East, Waterloo, ON, Canada N2J 1C4

E-mail: kapapp@probitymedical.com

Tel.: + 1-519-5799535

Fax: + 1-519-5798312 cacy and safety profiles suitable for the long-term treatment of patients with moderate to severe psoriasis.

Keywords Biological $\cdot$ Alefacept $\cdot$ Efalizumab · Etanercept $\cdot$ Infliximab $\cdot$ Long-term treatment . Psoriasis

\section{Introduction}

Psoriasis is a chronic inflammatory, immune-mediated disease characterized by periods of spontaneous remission and relapse [22]. Conventional nonbiological therapies for moderate to severe psoriasis, such as cyclosporine, methotrexate, and phototherapy, have proved effective in suppressing symptoms; and many dermatologists have at least a decade of experience using these treatment modalities [21]. Because of the chronic nature of psoriasis, many patients require lifelong symptom management. Conventional nonbiological systemic therapies have been successfully used as continuous therapy in some patients for extended periods (e.g., methotrexate); however, for some patients, the long-term use of these agents may be limited by known toxicities, including nephrotoxicity (cyclosporine) [21], hepatotoxicity (methotrexate) [10], skin cancer (psoralen-ultraviolet A phototherapy, or PUVA) [23], and prolonged teratogenicity (oral retinoids) [5].

Current treatment guidelines recommend limiting the administration of cyclosporine to short-term (3-month) intermittent therapy or to no longer than 1-2 years continuously [11], reducing the dosage and minimizing lifetime exposure to methotrexate and ultraviolet irradiation [12, 27], and avoiding treatment with oral retinoids and several other conventional antipsoriatic therapies in women of childbearing potential [4]. Available data suggest that, when used according to contemporary guidelines and with appropriate monitoring for toxicity, conventional nonbiological treatments can be reasonably safe and tolerable [29]. However, minimizing toxicity while still providing continuous control 
of psoriasis symptoms over a patient's lifetime represents a clinical challenge.

An improved understanding of the immunologic basis of psoriasis led to the development of several targeted biological therapies that attempt to address the challenge of providing long-term continuous disease control. The first biological agent approved for the treatment of adult patients with moderate to severe chronic plaque psoriasis, alefacept (Amevive ${ }^{\circledR}$, Biogen Idec Inc.), is currently registered for use in several countries, including the United States but not the European Union (EU). Two others, efalizumab (Raptiva ${ }^{\circledR}$, Genentech, Inc.; Serono International S.A.) and etanercept (Enbrel ${ }^{\circledR}$, Amgen, Inc.; Wyeth Pharmaceuticals), are also registered for this indication in multiple countries, including the EU and the United States. Another biological, infliximab (Remicade ${ }^{\circledR}$, Centocor, Inc.; Schering-Plough Corp.), has presented Phase III clinical trial data for the treatment of psoriasis and recently became registered for use in the EU. The clinical trials programs for these four agents have demonstrated their safety and efficacy in patients with psoriasis over an initial period of several months; longer-term results are now becoming available. One other biological agent, adalimumab (Humira ${ }^{\circledR}$, Abbott Laboratories), is at an earlier stage of development for psoriasis and has completed Phase II clinical trials for the disease. This article reviews the latest clinical data available regarding the long-term efficacy of these biological agents for treatment of psoriasis.

\section{Alefacept}

Alefacept is a fusion protein between human leukocyte function-associated antigen-3 (LFA-3) and the human $\mathrm{IgG}_{1}$ antibody $\mathrm{Fc}$ region. By binding to the $\mathrm{CD} 2$ antigen on $\mathrm{T}$ cells, alefacept prevents $\mathrm{T}$-cell activation and triggers apoptosis, preferentially targeting memory-effector $\mathrm{T}$ cells [3]. Alefacept has been evaluated as a weekly intravenous (IV) 7.5-mg administration and as a weekly intramuscular (IM) 15 -mg injection (Amevive ${ }^{\circledR}$ [alefacept] prescribing information; Cambridge, Mass: Biogen, Inc.; August 2004); however, only the IM dose is currently available. The efficacy and safety of a 12-week course of weekly IM alefacept $15 \mathrm{mg}$ were evaluated in a randomized, placebo-controlled Phase III trial of adult patients with chronic plaque psoriasis [minimum of $10 \%$ body surface area (BSA) affected by psoriasis] [15]. Two weeks after the treatment phase was completed (study week 14), the Psoriasis Area and Severity Index (PASI) improved by at least $75 \%$ from baseline (PASI-75) in $21 \%$ of the 166 patients who received alefacept $15 \mathrm{mg}$ per week, with $42 \%$ achieving at least a $50 \%$ improvement from baseline (PASI-50) (Amevive ${ }^{\circledR}$ [alefacept] prescribing information). This compares with rates of 5 and $18 \%$, respectively, for patients randomized to placebo $(n=168$; $P<0.001$ for both comparisons). Mean percentage PASI improvement from baseline for a course of alefacept 15-mg IM therapy is shown in Fig. 1.
Alefacept has demonstrated the longest psoriasis remission times among biological agents for psoriasis. Patients who achieved PASI-75 after a 12-week course of alefacept $15 \mathrm{mg}$ per week $(n=54)$ maintained at least a PASI-50 response for a median period of approximately 7 months [15]. Thus, the long-term use of alefacept as a remittive therapy has been explored through extension studies of additional treatment courses for patients who were enrolled in alefacept IV or IM Phase III trials. Efficacy data have been presented for up to five 12-week courses of alefacept therapy (i.e., approximately 60 weeks of treatment), although PASI responses are available for only the IV formulation [IM results were provided using Physician's Global Assessment (PGA)] (A. Menter et al., unpublished data presented at the 63rd Annual Meeting of the American Academy of Dermatology, 2005). The analyses were performed on the astreated patient population, and a patient was considered a responder if he or she achieved a response anytime during each 12-week treatment course. Using these criteria, PASI-75 response rates for IV alefacept increased from $29 \%$ during the first course of therapy $(n=521)$ to $54 \%$ during course $5(n=39)$. PGA response rates for the IM formulation increased from $21 \%$ of patients classified as "clear" or "almost clear" during course 1 ( $n=457)$ to $41 \%$ during course $4(n=100)$, but the response rate decreased to less than $30 \%$ during course 5 $(n=50)$.

Alefacept therapy appears to be well tolerated, even with long-term use. The primary concern with alefacept is T-lymphocyte depletion. Alefacept should not be initiated in patients with $\mathrm{CD} 4{ }^{+} \mathrm{T}$-lymphocyte counts below normal, and biweekly $\mathrm{CD} 4^{+} \mathrm{T}^{-}$-cell monitoring is recommended during each treatment course (Amevive ${ }^{\circledR}$ [alefacept] prescribing information). Alefacept should be withheld if T-cell counts fall below 250 cells $/ \mu 1$ and discontinued if they remain low for a month. Patients treated with alefacept during Phase III trials demonstrated a low incidence of malignancy, serious infections requiring hospitalization, and hypersensitivity reactions (Amevive ${ }^{\circledR}$ [alefacept] prescribing information). The integrated safety database for alefacept includes a total of 1,869 alefacept-treated psoriasis patients and includes patients who have received up to nine courses of alefacept therapy $(n=8)$ over a 5-year period. Despite the paucity of data for multiple treatment courses, the incidence of common adverse events (e.g., headache, nasopharyngitis, influenza, upper respiratory tract infection, and pruritus), serious adverse events, infections, malignancies, and autoantibody production appeared to fluctuate little with additional treatment, although the safety of long-term alefacept therapy will need to continue to be assessed.

\section{Efalizumab}

Efalizumab is a recombinant humanized monoclonal $\mathrm{IgG}_{1}$ antibody against the $\alpha$ subunit (CD11a) of LFA-1, 
ETANERCEPT

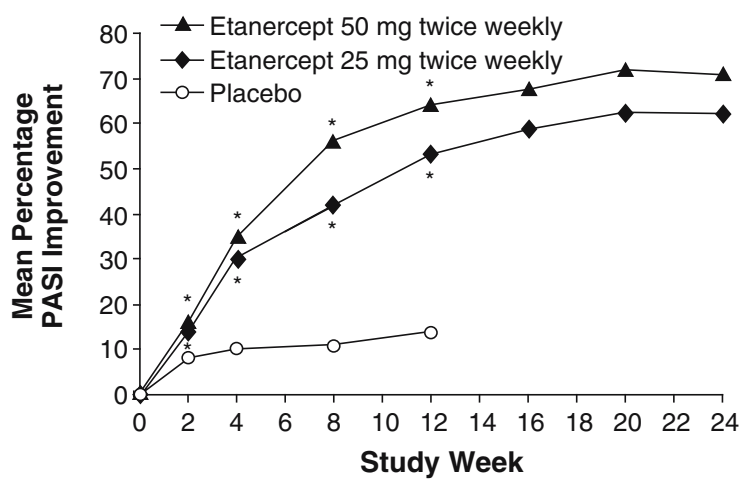

${ }^{*} \mathrm{P}<.001$ vs placebo.

ALEFACEPT

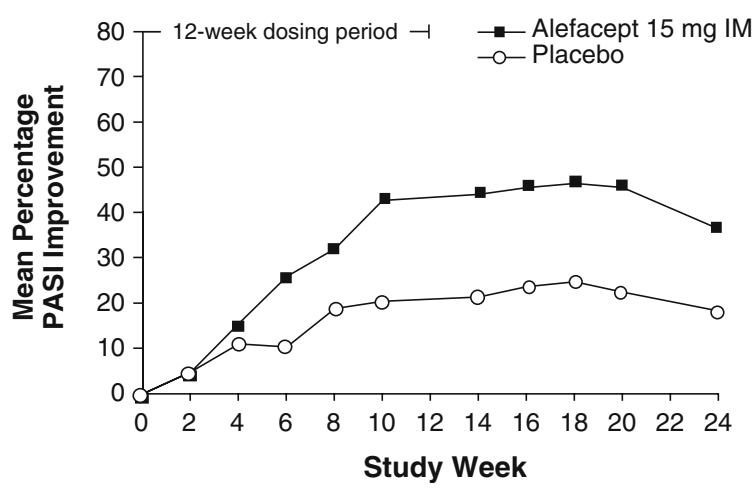

Fig. 1 Mean percentage psoriasis area and severity index $(P A S I)$ improvement from baseline in randomized placebo-controlled, Phase III studies of biological agents for the treatment of psoriasis. ETANERCEPT Results for etanercept 25 or $50 \mathrm{mg}$ twice weekly for 24 weeks [18]. Sample size at each PASI assessment was not reported. EFALIZUMAB Results for the use of efalizumab $1 \mathrm{mg} /$ $\mathrm{kg} /$ week for 12 weeks followed by a 12-week open-label extension phase $[6,19]$. The efficacy-evaluable population for this study included all patients randomized to efalizumab treatment $(n=369)$, which differs from other efalizumab trials (and those of the other agents discussed) that include only patients who received at least 1 dose of the study drug. Following are the sample sizes at each PASI

which modulates several key steps in the immunopathogenesis of psoriasis, including initial $\mathrm{T}$ cell activation, trafficking from the circulation into psoriatic lesions, and reactivation therein [13]. Multiple Phase III clinical trials have demonstrated the efficacy, safety, and health-related quality-of-life (HRQOL) benefits of 12 weeks of subcutaneous (SC) efalizumab therapy in patients with moderate to severe chronic plaque psoriasis $[6,16,20,24,28]$. As will be discussed later, available clinical data support the efficacy of extending efalizumab treatment beyond 12 weeks, as reflected in the European guidelines (European Medicines Agency: Raptiva [efalizumab] summary of product characteristics; http://www.emea.eu.int/humandocs/Humans/EPAR/ Raptiva/raptiv/htm; 2005).

The Phase III study that served as the basis for efalizumab labeling evaluated the efficacy and safety of

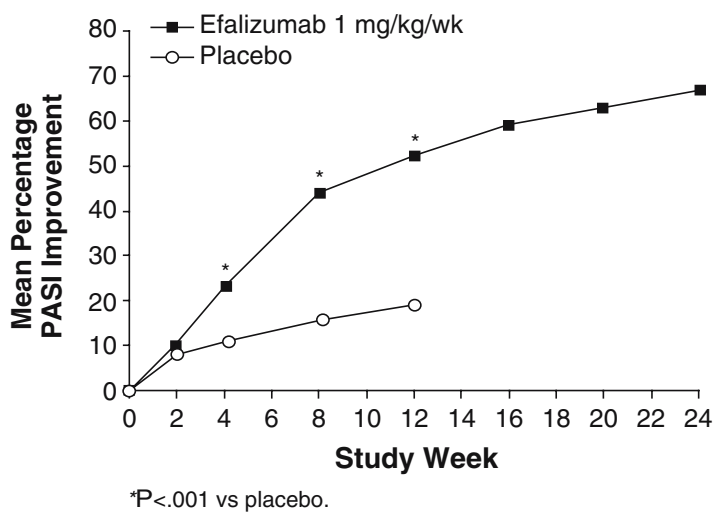

assessment, represented by the data points. For efalizumab: week 0 , 369 ; week 2, 357; week 4, 353; week 8, 352; week 12, 347; week 16, 322 ; week 20, 323; week 24, 312. For placebo: week 0, 187; week 2, 186; week 4, 184; week 8, 180; week 12, 175 [19]. ALEFACEPT Alefacept results for the available 15-mg intramuscular $(I M)$ dose [15]. Drug was administered weekly for 12 weeks, followed by observation for 12 weeks. In this study, 166 patients were randomized to receive alefacept $15 \mathrm{mg} \mathrm{IM}$ and 168 patients to receive placebo. Sample sizes at each PASI assessment were not provided. Statistical comparisons were not reported. Note Data for infliximab were not available

efalizumab $1 \mathrm{mg} / \mathrm{kg}$ weekly [6]. A total of 556 adult patients with moderate to severe chronic plaque psoriasis (baseline PASI $\geq 12.0$ and $\geq 10 \%$ BSA affected) were randomized to receive efalizumab $(n=369)$ or placebo $(n=187)$ double-blind for 12 weeks; all patients were then eligible to receive extended efalizumab open-label treatment for an additional 12 weeks [19]. A significant efalizumab treatment effect relative to placebo was achieved at 12 weeks, and extended treatment conferred additional clinical benefit. Using an intent-to-treat (ITT) analysis with the last observation carried forward (LOCF) for patients with missing data, the percentage of efalizumab-treated patients who achieved PASI-75 increased from $27 \%$ at week 12 (vs. $4 \%$ with placebo, $P<0.001)$ to $44 \%$ at week 24 . Similarly, the percentage of efalizumab-treated patients who achieved PASI-50 and PASI-90 increased from 59 to $67 \%$ and from 5 to 
$15 \%$ at weeks 12 and 24 , respectively. The mean percentage PASI improvement relative to baseline increased from $52 \%$ at week 12 to $67 \%$ at week 24 (Fig. 1) [6, 19]. Mean percentage PASI improvement appeared to increase throughout the 24-week duration without any evidence of a plateau effect. Two additional Phase III studies with similar placebo-controlled, double-blind initial 12-week treatment periods support the efficacy and safety of efalizumab therapy over 24 weeks [16, 17].

An open-label Phase III study evaluated the efficacy, safety, and tolerability of up to 36 months of continuous efalizumab treatment. At the time of this writing, results through 60 weeks of the trial and through 27 months (108 weeks) of the trial have been published [7, 9] and data through 36 months (144 weeks) have been presented (A.B. Gottlieb et al., unpublished results reported at the 63rd annual meeting of the American Academy of Dermatology, 2005). A total of 339 patients with moderate to severe plaque psoriasis received weekly efalizumab $2 \mathrm{mg} / \mathrm{kg}$ for 12 weeks; of the 308 patients who completed the initial treatment period, 290 patients $(94 \%)$ achieved PASI-50 or a static Physician's Global Assessment (sPGA) of mild, minimal, or clear at week 12 and were allowed to receive maintenance treatment with efalizumab $1 \mathrm{mg} / \mathrm{kg}$ per week for up to 33 additional months (132 weeks) [7, 9]. At completion of the first 12-week treatment period, $41 \%$ of patients achieved PASI-75. Preliminary results showed that, by week 60, PASI-75 responses were observed in $49 \%$ of the ITT population $(n=339)$ and in $57 \%$ of patients $(n=290$, last observation carried forward) who were analyzed by means of a maintenance group analysis, which included only patients eligible to receive continued efalizumab. An as-treated analysis indicated that $64 \%$ of patients $(n=228)$ achieved PASI75 at week 60 (PASI-75 results through week 48 are shown in Fig. 2) [7]. Results in this trial support the sustained efficacy of up to 36 months of continuous efalizumab treatment (A.B. Gottlieb et al., unpublished results reported at the 63rd annual meeting of the American Academy of Dermatology, 2005).

Some limitations of the 3-year study are noted. At initiation of the trial, the label-supported dosage of $1 \mathrm{mg} / \mathrm{kg}$ had not been established; thus, a dosage of $2 \mathrm{mg} / \mathrm{kg}$ was administered during the initial 3-month period. It was subsequently demonstrated that the safety and efficacy do not differ for the $1-$ and $2-\mathrm{mg} / \mathrm{kg}$ doses $[16,17]$. In addition, although relatively few patients were affected $(\leq 4 \%)$, a dose increase of up to $4 \mathrm{mg} / \mathrm{kg}$ was allowed up through 15 months of the study. Use of the LOCF procedure during analysis of ITT data might introduce bias in the final result; depending on the response of the patient, the bias could overestimate or underestimate the final result.

Clinical trials have shown that efalizumab is generally well tolerated and has a favorable safety profile over an initial 12-week treatment period [6, 16, 24, 28]. Results of the extended studies described here support the con- tinued safety and tolerability of efalizumab treatment periods longer than 12 weeks [7, 9, 16, 17, 19]. The most common adverse events associated with efalizumab administration are acute flulike symptoms (headache, chills, fever, myalgia, vomiting, and nausea) observed primarily following the first two doses. After the third and subsequent doses, the incidence of acute adverse events in efalizumab-treated patients is comparable to that observed in placebo recipients. The extended treatment studies have shown that, with the exception of an expected reduction in acute adverse events, the incidence and intensity of adverse events during the second and subsequent treatment periods are similar to those observed during the first 12 weeks. To date, no evidence of cumulative or end-organ toxicity has been found with efalizumab. Thrombocytopenia has been reported during efalizumab clinical trials (Raptiva ${ }^{\circledR}$ [efalizumab] package insert; South San Francisco, Calif: Genentech, Inc.; June 2005), and recently a statement about the development of hemolytic anemia has been added to the prescribing information (Raptiva ${ }^{\circledR}$ [efalizumab] package insert). Worsening of psoriasis and psoriasis variants has been observed in 3\% of efalizumab patients during therapy (i.e., generalized inflammatory flare), and in $14 \%$ of patients following abrupt discontinuation of efalizumab (i.e., rebound) [1]. The likelihood of experiencing rebound was inversely related to the PASI response at week $12 ; 72 \%$ of patients experiencing rebound were nonresponders, and only $10 \%$ had achieved PASI-75 [1]. New-onset or worsening arthritis has been infrequently reported during clinical trials and postmarketing (Raptiva ${ }^{\circledR}$ [efalizumab] package insert). Based on available clinical data from up to 36 months of continuous treatment, efalizumab does not appear to be associated with an increased risk of malignancy or opportunistic infections observed in immunosuppressed hosts [7, 16, 17, 19, 28]. Because the numbers of patients evaluated in the long-term studies have been relatively small, the incidence of malignancy and infection will be assessed postmarketing (Raptiva ${ }^{\circledR}$ [efalizumab] package insert).

\section{Etanercept}

Etanercept is a recombinant fusion protein comprising domains of the $75-\mathrm{kDa}$ human tumor necrosis factor (TNF) receptor and human $\mathrm{IgG}_{1}$, which inhibits the activity of TNF- $\alpha$, a proinflammatory cytokine implicated in psoriasis. The efficacy, safety, and HRQOL benefits of 12 and 24 weeks of etanercept therapy in patients with moderate to severe chronic plaque psoriasis (baseline PASI $\geq 10$ and $\geq 10 \%$ of BSA affected) have been demonstrated in Phase III clinical trials [18, 25]. There is also clinical experience with etanercept in other indications, such as rheumatoid arthritis (RA). Recommended dosage in the EU is $25 \mathrm{mg}$ administered SC twice weekly for up to 24 weeks. Dosing at $50 \mathrm{mg}$ twice weekly is also possible for the first 12 weeks followed by 


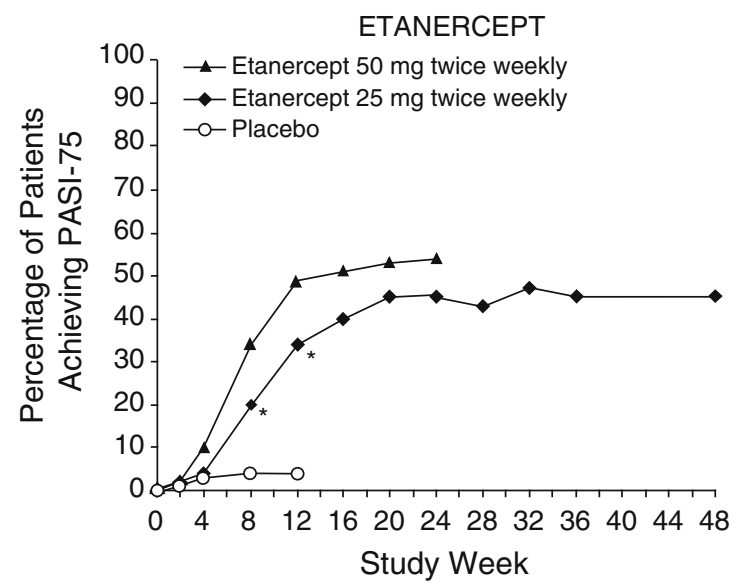

${ }^{*} \mathrm{P}<0.05$ vs placebo.

$P=0.0013$ vs placebo

$P<0.001$ vs placebo.

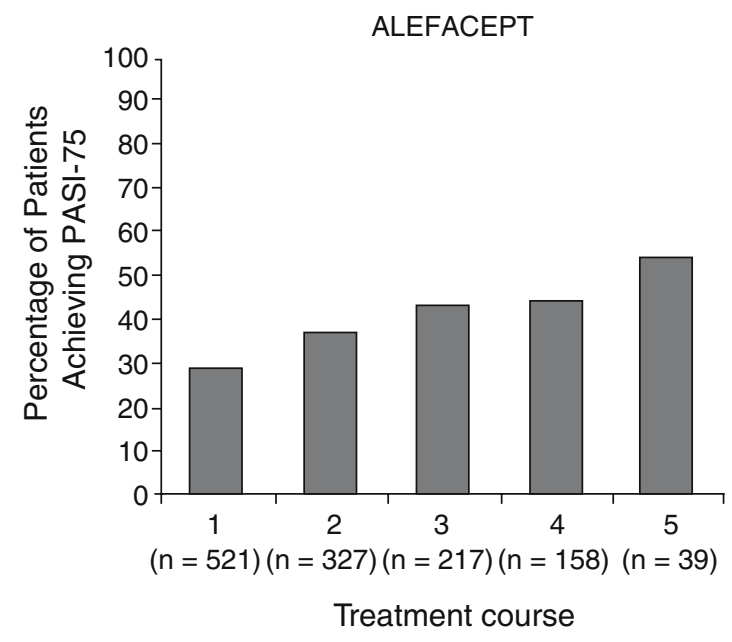

Fig. 2 Percentage of patients achieving 75\% improvement from baseline psoriasis area and severity index $(P A S I)$. Solid lines indicate intention-to-treat analyses; broken lines indicate as-treated analyses (efalizumab) or modified ITT analysis (infliximab) ETANERCEPT Results shown are from an etanercept study in which patients received etanercept $25 \mathrm{mg}(n=196)$, etanercept $50 \mathrm{mg}(n=194)$, or placebo $(n=193)$ twice weekly for 12 weeks followed by open-label etanercept $25 \mathrm{mg}$ twice weekly for up to 36 additional weeks [25]. Efficacy was evaluated in the ITT population. Published data beyond 24 weeks are not available; however, the data presented at several international medical congresses [e.g., European Academy of Dermatology and Venereology $(E A D V)$, American Academy of Dermatology $(A A D)]$ suggest that the additional efficacy initially achieved with etanercept $50 \mathrm{mg}$ twice weekly beyond that obtained with the 50-mg-per-week dose might not be sustained in the long term following dose reduction (unpublished data presented at the 2004 EADV and 2005 summer AAD meetings). EFALIZUMAB Results are shown for efalizumab from an open-label Phase III study $(n=339)$ of efalizumab $2 \mathrm{mg} / \mathrm{kg} /$ week for 12 weeks, followed by $1 \mathrm{mg} / \mathrm{kg} /$ week for up to 33 additional months in patients who achieved PASI-50 or a static Physician's Global Assessment $(s P G A)$ of mild, minimal, or clear at week 12 [7]. The dosage received during the first 12 weeks was higher than that later approved for clinical use $(1 \mathrm{mg} / \mathrm{kg} /$ week $)$. Efficacy was evaluated in the intent-to-treat (ITT) population throughout the study and is presented through 48 weeks; as-treated analysis is shown after
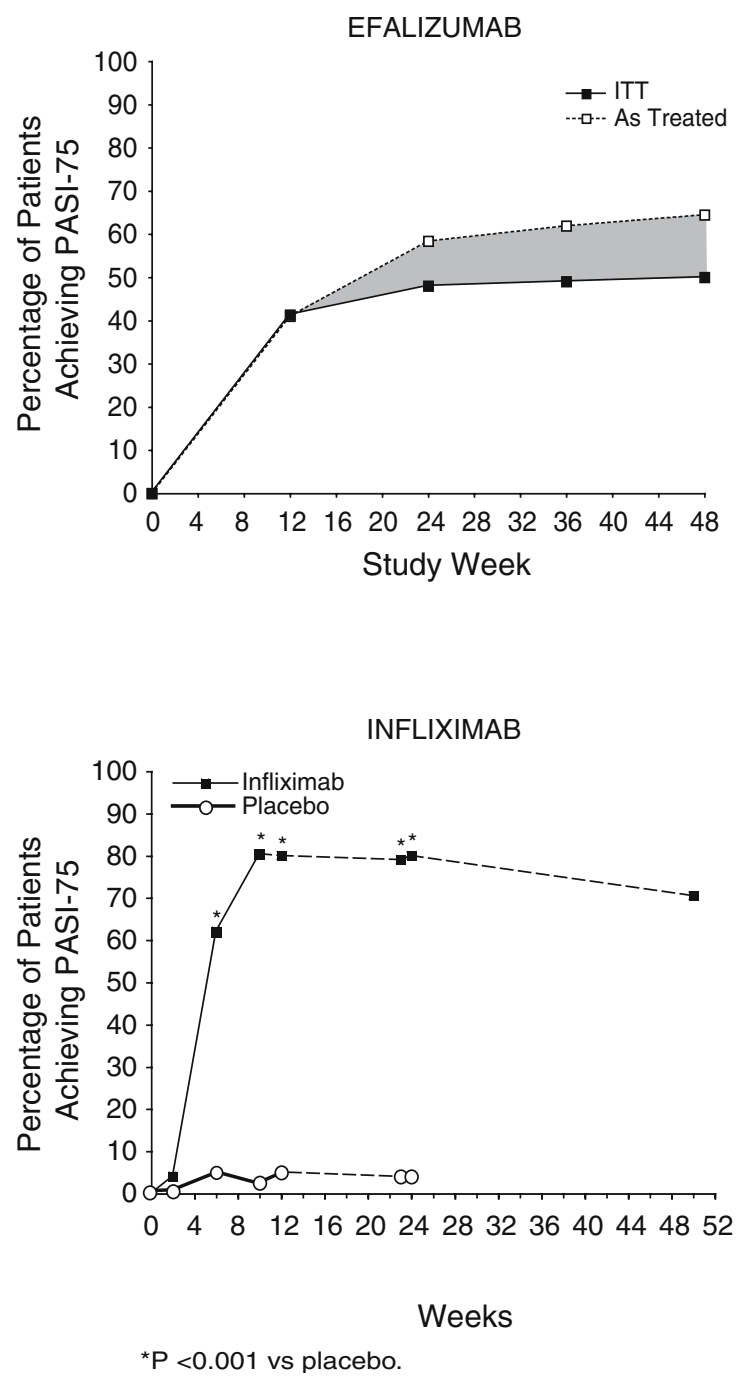

12 weeks through week 48 . Sample sizes for as-treated analysis are as follows: week 24, 290; week 36, 269; week 48, 247 [7]. The shaded portion specifies a response window framed by the most conservative measure of efficacy (ITT) and the response of patients that remain on therapy (as-treated). ALEFACEPT Results are shown for alefacept $7.5 \mathrm{mg}$ administered intravenously (IV) (A. Menter et al., unpublished data presented at the 63rd annual meeting of the American Academy of Dermatology); longterm PASI-75 response rates for the alefacept intramuscular (IM) dosing regimen have not been reported. Each course represents 12 weekly alefacept infusions followed by a minimum of 12 weeks of treatment-free observation. The second course was initiated 12 weeks after the first course [14]; additional treatment courses were initiated when the patient was deemed by the investigator to require systemic therapy or phototherapy for psoriasis recurrence. Course 5 represents patients who may have received up to 60 total weeks of alefacept treatment. Sample sizes are as-treated numbers. INFLIXIMAB Results are shown for infliximab patients who were randomized to receive IV infliximab $5 \mathrm{mg} / \mathrm{kg}$ or placebo at initiation, week 2 , week 6 , and then every 8 weeks through week 46 [26]. Analyses through week 10 were performed using the ITT population (infliximab, $n=301$; placebo, $n=77$ ); analyses through week 50 were based on a "modified ITT" population $(n=234)$ where missing data were considered as nonresponse for patients who withdrew from the study due to preselected reasons (mainly related to lack of efficacy; patients who withdrew for other reasons were omitted from the analysis) 
a "step-down" to $25 \mathrm{mg}$ twice weekly. Based on published clinical data, European guidelines indicate that nonresponders should discontinue etanercept after 12 weeks and that reinitiation of etanercept treatment is possible after discontinuation (European Medicines Agency. Enbrel [etanercept] summary of product characteristics; http://www.emea.eu.int/humandocs/Humans/ EPAR/enbrel/enbrel.htm; 2005). In the United States, a 50 -mg prefilled syringe recently became available, and the recommended dosing of etanercept is $50 \mathrm{mg}$ twice weekly for the first 12 weeks of treatment, followed by step-down to $50 \mathrm{mg}$ once weekly (Enbrel ${ }^{\circledR}$ [etanercept] package insert; Thousand Oaks, Calif: Immunex Corporation; October 2005).

A placebo-controlled, double-blind Phase III study demonstrated the safety and efficacy of 12 and 24 weeks of etanercept treatment [18]. A total of 672 patients were randomized 1:1:1:1 to receive placebo or etanercept $25 \mathrm{mg}$ once weekly, $25 \mathrm{mg}$ twice weekly, or $50 \mathrm{mg}$ twice weekly via SC injection for 12 weeks. Etanercept recipients who completed the initial treatment period continued on their assigned dosage for an additional 12 weeks. Whereas efficacy was originally reported only in patients who received at least 1 dose of study drug $(n=652)$ [18], some data were subsequently reanalyzed for all patients who were enrolled and randomized, irrespective of whether the study drug was administered $\left(\right.$ Enbrel $^{\circledR}$ [etanercept] package insert). These data are discussed herein to allow for a more accurate comparison with ITT data from efalizumab clinical trials. This reanalysis showed that among patients randomized to receive etanercept 25 or $50 \mathrm{mg}$ twice weekly (the dosages most similar to those now recommended in Europe and the United States), 32 and $47 \%$ of patients, respectively, achieved PASI-75 at week 12, increasing to 41 and $54 \%$ at week 24 (Enbrel ${ }^{\circledR}$ [etanercept] package insert). The mean percentage PASI improvement reported in patients who received at least 1 dose of etanercept 25 or $50 \mathrm{mg}$ increased from 53 to $64 \%$, respectively, at week 12 to 62 and $71 \%$ at week 24 . However, it appears that the mean percentage PASI improvement began to plateau around week 20 (Fig. 1).

Results from the first 24 weeks of a 48 -week continuous etanercept therapy global Phase III psoriasis study were recently published. In the initial 12 -week, placebocontrolled, double-blind phase of the study, 611 patients were randomized $1: 1: 1$ to receive placebo or etanercept 25 or $50 \mathrm{mg}$ twice weekly; all patients were then eligible to receive open-label etanercept $25 \mathrm{mg}$ twice weekly for up to 36 additional weeks. Results at 12 and 24 weeks were reported for all randomized patients who received at least 1 dose of study drug $(n=583)$ using the LOCF procedure for analysis and for all randomized patients regardless of whether they received study drug $(n=611)$, with the assumption that patients with missing data had not met the criteria for response at that end point [25]. At 12 weeks, 32 and $46 \%$ of all patients randomized to receive etanercept 25 or $50 \mathrm{mg}$ twice weekly, respectively, achieved PASI-75 (vs. $3 \%$ for placebo, $P<0.0001$ both comparisons). The PASI-75 response rate was slightly higher among patients who received at least 1 dose of etanercept 25 or $50 \mathrm{mg}$ (34 and $49 \%$, respectively), increasing to 45 and $54 \%$ at week 24 [25]. Data presented for this study at scientific meetings [2004 meeting of the European Academy of Dermatology and Venereology [EADV] and 2005 meeting of the American Academy of Dermatology (AAD)] indicated that among patients continuing on etanercept $25 \mathrm{mg}$ twice weekly, the PASI-75 response achieved at week 24 was maintained through week 48 of continuous treatment and suggested that the greater PASI-75 response rate initially observed after 24 weeks in the group initially randomized to etanercept $50 \mathrm{mg}$ twice weekly decreased slightly after per-protocol dose reduction, with PASI-75 response rates reaching a similar level in both groups during the open-label treatment phase (W. Sterry, unpublished data).

A randomized, placebo-controlled, multicenter Phase III study to evaluate the safety and efficacy of etanercept $50 \mathrm{mg}$ twice weekly over the course of 2 years is currently ongoing. Preliminary results after 48 weeks of therapy were recently reported (S.K. Tyring et al., unpublished data presented at the summer meeting of the American Academy of Dermatology, 2005). In this trial, patients were randomized to receive either etanercept $50 \mathrm{mg}(n=311)$ or placebo twice weekly for 12 weeks $(n=307)$, followed by open-label etanercept $50 \mathrm{mg}$ twice weekly. Etanercept demonstrated statistically significant improvements in PASI response rates compared with placebo by week 4 of therapy. Response rates continued to increase through 24 weeks of therapy, after which they appeared to plateau. Approximately $60 \%$ of patients achieved a PASI-75 response at week 24 , with a similar proportion at week 48 .

Clinical data support the safety and tolerability of 12-24 weeks of etanercept treatment in patients with psoriasis $[18,25]$. Published results from psoriasis clinical trials showed that etanercept was generally well tolerated. Adverse events observed during the initial 12-week placebo-controlled period were typically mild to moderate in intensity and occurred with similar frequency in etanercept and placebo groups [18, 25]. No apparent change in the adverse events profile occurred during the second 12-week period of the trials [18, 25].

Safety outcomes of the long-term Phase III psoriasis clinical trial, particularly for patients who received $50 \mathrm{mg}$ twice weekly, have not yet been presented in detail; however, a preliminary analysis integrating data from the Phase II and 2 Phase III etanercept clinical trials, in which many patients received the 25 -mg dosage, suggested that no new pattern of adverse events emerged during up to 60 weeks of treatment (A.B. Gottlieb et al., unpublished data presented at the 62nd annual meeting of the American Academy of Dermatology, 2004). Psoriasis clinical trials revealed no evidence of increased risk of opportunistic infections, tuberculosis, or skin cancers during up to 60 weeks of etanercept treatment (A.B. Gottlieb et al., unpublished data, 2004). Whereas 
long-term data from clinical trials in many patients receiving etanercept for other indications, such as RA, support the general safety and tolerability of the $25-\mathrm{mg}$ dosage, there have been infrequent cases of tuberculosis and rare cases of demyelinating disorders, pancytopenia, and congestive heart failure (Enbrel ${ }^{\circledR}$ [etanercept] package insert, European Medicines Agency; Enbrel [etanercept] summary of product characteristics; http:// www.emea.eu.int/humandocs/Humans/EPAR/enbrel/ enbrel.htm; 2005).

\section{Infliximab}

Infliximab, a chimeric monoclonal antibody that binds membrane-bound and soluble TNF- $\alpha$, is still under evaluation for use in patients with psoriasis. Infliximab has demonstrated efficacy in psoriasis patients in randomized, placebo-controlled Phase II trials [2, 8]. However, the results of an international multicenter, randomized, placebo-controlled Phase III trial of adult patients with plaque psoriasis (baseline PASI $\geq 12$ and $\geq 10 \%$ of BSA affected) were recently reported [26]. Patients were randomized to receive IV infliximab $5 \mathrm{mg} / \mathrm{kg}$ $(n=301)$ or placebo $(n=77)$ at initiation, week 2 , and week 6 and then every 8 weeks through week 46 . The placebo group crossed over to infliximab treatment at week 24, but the study remained blinded throughout. Patients who discontinued the study early because of lack or loss of response or for whom insufficient data were available were treated as not achieving the end points for analysis of the ITT population. At week 10 of treatment, the PASI-75 response rate was $80.4 \%$ in the infliximab-treated group and $2.6 \%$ in the placebo-treated group. This level of response was sustained through week 24. At week 50, the proportion of the ITT population that achieved PASI-75 dropped to $60.5 \%$. However, excluding patients who missed 2 infusions, the PASI-75 rate at week 50 was $70.5 \%(n=234)$. The reason for the moderate reduction in efficacy is unclear but may be due to the development of inhibitory antibodies in a percentage of the patients.

The safety profile for infliximab during this extended treatment Phase III trial appears to be comparable to those observed during earlier studies [26]. The incidence of adverse events and serious adverse events in infliximab-treated patients was slightly elevated relative to those in placebo recipients through the first 24 weeks of treatment, and one patient who received infliximab died of sepsis. Elevations in aminotransferases were also observed in some infliximab-treated patients. In this trial, infection rates were comparable between the treated and placebo groups; however, like etanercept, postmarketing data from infliximab-treated patients with RA, Crohn's disease, or other indications for which infliximab is approved suggest a potential increased risk for events such as opportunistic infections (e.g., tuberculosis), lymphoma, or congestive heart failure.

\section{Adalimumab}

Adalimumab is a fully human monoclonal antibody that binds TNF- $\alpha$. It is currently being evaluated in Phase III clinical studies for the treatment of moderate to severe plaque psoriasis. Results from a Phase II randomized, double-blind, placebo-controlled, multicenter clinical trial have been presented (K.B. Gordon et al., unpublished data presented at the 62nd annual meeting of the American Academy of Dermatology, 2004). Patients were randomized to receive placebo $(n=52)$ or adalimumab, either an 80-mg first dose followed by $40 \mathrm{mg}$ every other week (EOW; $n=46$ ) or an 80 -mg first and second dose followed by $40 \mathrm{mg}$ every week $(n=50)$, for 12 weeks. In the preliminary analysis and presentation, 53 and $80 \%$ of the patients receiving adalimumab EOW or every week, respectively, achieved a PASI-75 response, compared to $4 \%$ of the patients receiving placebo $(n=52)$. However, a careful reanalysis of the data suggested that the true efficacy was several percentage points lower (R.G.B. Langley et al., unpublished data, presented at the Fall European Academy of Dermatology and Venereology, 2005). Adverse events were similar to placebo, with headache, injection site pain, nausea, elevated triglycerides, cough, sinus congestion, and fatigue most common. Injection site pain was more frequent in the adalimumab $40-\mathrm{mg} /$ week group (12\%) than in the placebo group (6\%).

\section{Comparison of biological agents}

In the absence of head-to-head clinical trials, it is difficult to accurately compare the efficacy of the biological agents for psoriasis. However, most of these agents use comparable evaluations of treatment efficacy. Alefacept is an exception, as it is used as remittive therapy; and alefacept data are presented using the as-treated population and "response at any time" analyses. Thus, although alefacept appears to maintain efficacy in responsive patients over multiple courses of treatment (Fig. 2), its efficacy cannot be readily compared with efalizumab, etanercept, or infliximab.

Available long-term data indicate that the improvements in psoriasis achieved during the first 12-24 weeks of efalizumab therapy are maintained or improved through at least 60 weeks of continuous treatment. Data support the efficacy of efalizumab through at least 36 months of continuous treatment. The efficacy of etanercept $25 \mathrm{mg}$ administered twice weekly appears to be maintained through at least 48 weeks of continuous treatment. Preliminary findings of the PASI-75 response rate in patients who "step down" from etanercept $50 \mathrm{mg}$ twice weekly to $25 \mathrm{mg}$ twice weekly suggest that the initial improvements achieved with etanercept $50 \mathrm{mg}$ twice weekly beyond what is observed with the $25-\mathrm{mg}$ twice-weekly dose are slightly reduced following the recommended dose reduction. For infliximab, the very 
high response rates obtained after 10 weeks of treatment appear to be sustained through 24 weeks but show a moderate reduction through 48 weeks with infusions every 8 weeks. Week 48 PASI-75 response rates were $62 \%$ for efalizumab-treated patients and approximately $45 \%$ for etanercept-treated patients (as-treated populations; Fig. 2). The PASI-75 response rate at week 50 for infliximab was $70.5 \%$ in patients who did not miss more than 1 infusion (Fig. 2).

The longer-term studies summarized here are not directly comparable because of differences in patient eligibility for initial enrollment and maintenance treatment and inclusion in efficacy analyses. For example, in contrast to the long-term etanercept study, patients in the efalizumab open-label trial were eligible for maintenance treatment only if they achieved a reasonable response during the first 12 weeks. This included the majority $(94 \%)$ of patients completing the initial treatment phase. For the ITT efficacy analyses (presented through 12 weeks), all efalizumab-treated patients were included, even those who did not achieve PASI-50 or sPGA of mild, minimal, or clear at week 12 and were required to discontinue the trial. Direct data comparisons are further compromised by the available analyses. Efalizumab data are presented as both an ITT analysis for 48 weeks and an as-treated analysis for weeks 12 through 48. Etanercept data are presented as an ITT analysis through 48 weeks. Results from the long-term infliximab study are presented as an ITT analysis for the first 10 weeks of the trial and thereafter are presented as a "modified ITT" population, where missing data were considered as nonresponsive for patients who withdrew from the study for preselected reasons.

Given that psoriasis is a chronic, incurable disease, the availability of long-term data is critical for dermatologists evaluating treatment options. There is a paucity of long-term data derived from robust clinical trials for conventional nonbiological psoriasis therapies; therefore, dermatologists generally rely on treatment guidelines and personal experience in making their decisions about long-term administration of therapies such as methotrexate and cyclosporine. Because biologicals represent a new approach to the management of psoriasis, long-term data are of particular importance for this therapeutic class. Alefacept appears to be an effective therapy for inducing extended remissions in a small population of patients, and it has a demonstrated safety profile for remittive use. The long-term data available to date for efalizumab indicate that initial improvements in psoriasis are sustained for up to 36 months. Data from multiple clinical trials indicate that $22-41 \%$ of patients achieved PASI-75 in the first 3 months of therapy [6, 7, 16, 17, 24]; in an extended trial of patients receiving continuous therapy up to 36 months, $45.4 \%$ of the patients achieved PASI-75 at the 36-month end point (C.L. Leonardi et al., manuscript in preparation). Studies evaluating the long-term use of etanercept are under way, but only limited data are currently available, as suggested by the current 24-week limit for etanercept therapy in Europe. At 12 weeks, $49 \%$ of patients who received etanercept $50 \mathrm{mg}$ twice weekly achieved PASI-75 [25]. Available data suggest that improvements are maintained for 48 weeks, as $60 \%$ of patients receiving $50 \mathrm{mg}$ twice weekly achieved PASI-75 (S.K. Tyring et al., unpublished data presented at the summer meeting of the American Academy of Dermatology, 2005). Importantly, the safety data reported to date indicate that the safety profiles of efalizumab and etanercept allow for continuous long-term administration. Infliximab has demonstrated excellent response rates with induction and extended therapy, with an every-8-week infusion schedule optimal.

The approval of biological therapies, that is, the T-cell-modulators alefacept and efalizumab and the $\mathrm{TNF} \alpha$ antagonist etanercept, along with the development of other TNF $\alpha$ antagonists such as infliximab and adalimumab, represent significant advances for the management of psoriasis. Their efficacy and safety profiles suggest that they may be suitable for remittive or continuous long-term administration, providing dermatologists with new options for the long-term management of their patients with psoriasis. The safety and efficacy data from ongoing clinical trials and the experience of dermatologists are important to define further how these agents can best be integrated into the psoriasis armamentarium.

Acknowledgment The author recognizes the contributions of Kirsten Duncan, PharmD, in the development of this manuscript.

\section{References}

1. Carey W, Glazer S, Gottlieb AB et al (2006) Relapse, rebound, and psoriasis adverse events: an advisory group report. J Am Acad Dermatol 54(4 suppl 1):S171-S181

2. Chaudhari U, Romano P, Mulcahy LD, Dooley LT, Baker DG, Gottlieb AB (2001) Efficacy and safety of infliximab monotherapy for plaque-type psoriasis: a randomised trial. Lancet 357(9271): 1842-1847

3. Ellis CN, Krueger GG (2001) Treatment of chronic plaque psoriasis by selective targeting of memory effector $\mathrm{T}$ lymphocytes. N Engl J Med 345:248-255

4. Gollnick HP (1996) Oral retinoids - efficacy and toxicity in psoriasis. Br J Dermatol 125 (suppl 49):6-17

5. Gollnick HP, Dummler U (1997) Retinoids. Clin Dermatol 15:799-810

6. Gordon KB, Papp KA, Hamilton TK et al (2003) Efalizumab for patients with moderate to severe plaque psoriasis: a randomized controlled trial. JAMA 290:3073-3080

7. Gottlieb AB, Gordon KB, Lebwohl MG et al (2004) Extended efalizumab therapy sustains efficacy without increasing toxicity in patients with moderate to severe chronic plaque psoriasis. $\mathbf{J}$ Drugs Dermatol 3:614-624

8. Gottlieb AB, Evans R, Li S et al (2004) Infliximab induction therapy for patients with severe plaque-type psoriasis: a randomized, double-blind, placebo-controlled trial. J Am Acad Dermatol 51:534-542

9. Gottlieb AB, Hamilton T, Caro I et al (2006) Long-term continuous efalizumab therapy in patients with moderate to severe chronic plaque psoriasis: updated results from an ongoing trial. J Am Acad Dermatol 54(4 suppl 1):S154-S163 
10. Griffiths CE, Clark CM, Chalmers RJ, Li Wan PA, Williams $\mathrm{HC}$ (2000) A systematic review of treatments for severe psoriasis. Health Technol Assess 4:1-125

11. Griffiths CE, Dubertret L, Ellis CN et al (2004) Ciclosporin in psoriasis clinical practice: an international consensus statement. Br J Dermatol 150(suppl 67):11-23

12. Honigsmann $\mathrm{H}$ (2001) Phototherapy for psoriasis. Clin Exp Dermatol 26:343-350

13. Jullien D, Prinz JC, Langley RGB et al (2004) T-cell modulation for the treatment of chronic plaque psoriasis with efalizumab (Raptiva ${ }^{\mathrm{TM}}$ ): mechanisms of action. Dermatology 208:297-306

14. Krueger GG, Papp KA, Stough DB, Loven KH, Gulliver WP, Ellis CN (2002) A randomized, double-blind, placebo-controlled phase III study evaluating efficacy and tolerability of 2 courses of alefacept in patients with chronic plaque psoriasis. J Am Acad Dermatol 47:821-833

15. Lebwohl M, Christophers E, Langley R, Ortonne JP, Roberts J, Griffiths CE (2003) An international, randomized, doubleblind, placebo-controlled phase 3 trial of intramuscular alefacept in patients with chronic plaque psoriasis. Arch Dermatol 139:719-727

16. Lebwohl M, Tyring SK, Hamilton TK et al (2003) A novel targeted T-cell modulator, efalizumab, for plaque psoriasis. $\mathrm{N}$ Engl J Med 349:2004-2013

17. Leonardi CL, Papp KA, Gordon KB et al (2005) Extended efalizumab therapy improves chronic plaque psoriasis: results from a randomized phase III trial. J Am Acad Dermatol 52(3 Pt 1):425-433

18. Leonardi CL, Powers JL, Matheson RT et al (2003) Etanercept as monotherapy in patients with psoriasis. N Engl $\mathbf{J}$ Med 349:2014-2022

19. Menter A, Gordon K, Carey W et al (2005) Efficacy and safety observed during 24 weeks of efalizumab therapy in patients with moderate to severe plaque psoriasis. Arch Dermatol 141:31-38

20. Menter A, Kosinski M, Bresnahan BW, Papp KA, Ware JE Jr (2004) Impact of efalizumab on psoriasis-specific patient- reported outcomes. Results from three randomized, placebocontrolled clinical trials of moderate to severe plaque psoriasis. J Drugs Dermatol 3:27-38

21. Naldi L, Griffiths CE (2005) Traditional therapies in the management of moderate to severe chronic plaque psoriasis: an assessment of the benefits and risks. Br J Dermatol 152:597-615

22. Nickoloff BJ, Nestle FO (2004) Recent insights into the immunopathogenesis of psoriasis provide new therapeutic opportunities. J Clin Invest 113:1664-1675

23. Nijsten TE, Stern RS (2003) The increased risk of skin cancer is persistent after discontinuation of psoralen + ultraviolet A: a cohort study. J Invest Dermatol 121:252-258

24. Papp KA, Bressinck R, Fretzin S et al (2005) Safety of efalizumab in adults with chronic moderate to severe plaque psoriasis: a phase IIIb, randomized, controlled trial. Int J Dermatol [Epub ahead of print] Available at: http:// www.blackwell-synergy.com/doi/abs/10.1111/j.13654632.2006.02777.x

25. Papp KA, Tyring S, Lahfa M et al (2005) A global phase III randomized controlled trial of etanercept in psoriasis: safety, efficacy, and effect of dose reduction. Br J Dermatol 152:1304 1312

26. Reich K, Nestle FO, Papp K et al.; EXPRESS study investigators (2005) Infliximab induction and maintenance therapy for moderate-to-severe psoriasis: a phase III, multicentre, doubleblind trial. Lancet 366:1367-1374

27. Roenigk HH Jr, Auerbach R, Maibach H, Weinstein G, Lebwohl M (1998) Methotrexate in psoriasis: consensus conference. J Am Acad Dermatol 38:478-485

28. Sterry W, Dubertret L, Papp K, Chimenti S, Larsen CG (2004) Efalizumab for patients with moderate to severe chronic plaque psoriasis: results of the international, randomized, controlled phase III clinical experience Raptiva (CLEAR) trial. J Invest Dermatol 123(2):A64

29. Yamauchi PS, Rizk D, Kormeili T, Patnaik R, Lowe NJ (2003) Current systemic therapies for psoriasis: where are we now? J Am Acad Dermatol 49(Suppl 2):S66-S77 